\title{
Entre un no-tiempo y un no-lugar. El estatuto de la política en Utopía de Tomás Moro*
}

\author{
Between a no-time and a no-place. The Statute of \\ Politics in Thomas More's Utopia
}

Entre um não-tempo e um não-lugar. O estatuto da política em Utopia, de Thomas More

Dr. Ricardo Laleff Ilieff**

\begin{abstract}
RESUMEN
El presente trabajo retoma ciertos trazos de Utopía, en vistas de indagar acerca del rol de la política en su trama, es decir, cómo se inserta y cuáles son sus áreas de competencia. En ese marco, se destaca no solo la variable crítica del género que el escrito de Tomás Moro inaugura, sino también el vínculo particular que en él se establece entre espacialidad y tiempo. Así, este trabajo argumenta sobre una suerte de subsunción del rol de los magistrados - y de su capacidad decisoria - en la familia, lo que obliga a interrogar el problema de la administración y la agencia del individuo. Para ello se toma como referencia la cuestión del suicidio y de la pena de muerte, en tanto allí se condensa una visión sobre la política que obtura la emergencia de cualquier forma de dislocación en la organización comunitaria.
\end{abstract} Palabras clave: utopía, Moro, política, familia, suicidio

\section{SUMMARY}

This piece touches on certain traits of Utopia in order to delve Keywords: utopia, into how politics are inserted into the plot and how this is dealt Moro, politics, family, suicide

\footnotetext{
* Muchas de las ideas aquí vertidas son el producto, en gran medida, de mis años de formación docente con el profesor Juan Manuel Marzullo. A él, todo mi agradecimiento. ** Argentino. Doctor en Ciencias Sociales por la Universidad de Buenos Aires (UBA). Investigador del CONICET con sede en el Instituto de Investigaciones Gino Germani de la UBA. Docente de grado y posgrado en dicha casa de estudio. Contacto: ricardo.laleffilieff@coniet.gov.ar ORCID: https://orcid.org/0000-0002-9058-6580
} 
with. The critical variable of this genre that debuts in Tomás Moro's writing stands out, as does the particular link that is established between spatiality and time. In that way, this piece argues about a kind of subsumption of the role of magistrates and their decision-making capacity in the family. That forces us to question the problem of the administration and the agency of the individual. For that reason, the question of suicide and the death penalty is taken as a reference. There he condenses a vision about the policy that blocks the emergence of any form of dislocation in the community organization.

\section{RESUMO}

O presente trabalho retoma certos traços do livro Utopia, visanPalavras-chave: do indagar sobre a função da política em sua trama, isto é, como se insere e quais são suas áreas de competência. Nesse contexto, destaca-se não somente a variável crítica do gênero que a obra utopia, More, política, família, suicídio de Thomas More inaugura, mas também o vínculo particular que se estabelece nela entre espacialidade e tempo. Assim, este trabalho argumenta sobre uma espécie de subordinação da função dos magistrados —e de sua capacidade de tomar decisões- na família, o que obriga a questionar o problema da administração e a agência do indivíduo. Para isso, toma-se como referência a questão do suicídio e da pena de morte, enquanto se condensa aí uma visão sobre a política que obtura a emergência de qualquer forma de deslocação na organização comunitária. 
Eludimos las precisiones inútiles. No hay cronología ni historia. No hay tampoco estadísticas. Me has dicho que te llamas Eudoro;

yo no puedo decirte cómo me llamo, porque me dicen alguien. - ¿Y cómo se llamaba tu padre? -No se llamaba.

Borges, JoRge LuIS. “UTOPÍA DE UN HOMBRE QUE ESTÁ CANSADO”.

\section{Introducción}

Leído como el producto de la ironía (Sánchez 2011; White), del sarcasmo o del humor de su autor (Prévost), y hasta como una sátira (Heiserman; Wooden), una parábola (Bouyer), un diálogo entre personajes que representan paradigmas opuestos (Bevington; Engeman) y una distopía (Fueyo) dentro de una utopía (Le Guin), el célebre texto de Tomás Moro habilita toda clase de lecturas. Sin embargo, ello no hace más que evidenciar la imposibilidad de que alguna de ellas pueda fijar el sentido último de su contenido. Máxime si -parafraseando al decir de Leo Strauss (2009) - consideramos que lo esotérico habilita la observancia de aspectos recónditos o reservados para unos pocos lectores atentos. Pero, precisamente por este carácter abierto de Utopía, es posible dirigirse a sus páginas y hacer una lectura siempre renovada.

De manera que aquí no pretendemos deshabilitar o impugnar determinados abordajes que bien legan observaciones de lo más interesantes sobre este escrito de 1516; mucho menos prometer un camino de verdad sobre su mensaje o explicitar una apuesta metodológica que, en todo caso, lo convertiría en el objeto de una reflexión derivada. ¿Qué es, entonces, lo que motiva esta breve comunicación? Reparar en algunos rasgos constitutivos del género utópico y relevar el particular vínculo que entre política y tiempo se teje en el decir de Moro. En este sentido, comenzaremos explicitando la dimensión espacial y temporal de Utopía para luego, en los apartados subsiguientes, adentrarnos en dos aspectos que atraviesan la formulación de una forma política que, en verdad, no es tal debido a la visión sobre el conflicto que allí impera y al tipo de agencia que el autor le atribuye al individuo. En ese marco, repararemos específicamente en el problema del suicidio ${ }^{1}$.

1 Si bien hemos apelado a distintas traducciones de Utopía - como las de Emilio García Estebanez de la editorial Técnos, y la de Joaquim Mallafrè Gavaldà y Vicente Cam- 


\section{Espacio y tiempo}

Paul Ricoeur señaló que las utopías funcionan como dispositivos que se despliegan de una forma peculiar: enajenan su propio relato sin dejar nunca de reconocerse en esa enajenación. Paradoja esta que solo se explica desde la marca topológica que proponen al crear un afuera, un lugar externo de enunciación que imputa al presente, que lo señala no solo como ancla de reflexión histórica, sino también como problema específico. De allí que las utopías se estructuren desde una marcada politicidad. Es que, como bien afirma dicho autor francés, desde "ese 'ningún lugar"' que se esgrime puede "echarse una mirada al exterior, a nuestra realidad", dando lugar así a "otras maneras posibles de vivir" (1989 58), como si la política necesitara de la imaginación, de la fantasía, en su tarea siempre degradada de lidiar con los asuntos mundanos ${ }^{2}$.

En otras palabras, las utopías habilitan un desdoblamiento que no es más que el anverso y el reverso de un mismo cuadro: ese lugar real, empírico, que se impugna o se señala por defectuoso, es el punto de partida y de llegada de la tematización sobre ese espacio deseable pero inexistente ${ }^{3}$. Se trata, entonces, de un rasgo eminentemente crítico que, en el caso de la obra de Moro, se verifica desde sus primeras páginas o, al menos, desde el inicio del libro primero, allí cuando reyes, señores feudales, generales, sacerdotes y consejeros no escapan a las implacables detracciones que ofrece Rafael Hitlodeo, navegante portugués que relata, ya en el libro segundo, la forma de vida perfecta.

Lo que nos interesa remarcar aquí es que lo que acontece en la isla de Gran Bretaña y en la isla de Utopía denotan un mismo asunto: la organización social. En este aspecto reside gran parte de la singularidad del planteo de Moro y la relevancia de su visión sobre la política. Es que su crítica a la Inglaterra del siglo XVI comienza a ser evidente al recalcarse los problemas que la extensión de la explotación ovina implica, como por ejemplo el desplazamiento de familias enteras del lugar que

pos de Ariel- hemos trabajado principalmente con la ya clásica de Ramón Esquerra. Asimismo, hemos cotejado con la edición de habla inglesa de Norton Critical Edition.

2 Para mayor información sobre la utopía en el decir de Ricoeur, ver: Mauricio Beuchot y Micaela Cuesta.

3 Para Vittor Comparatto, es "un relato, directo o indirecto, de una realidad vista" (10). 
cultivaron sus antepasados. El pensador londinense encuentra, en ese proceso, el origen de la inequidad social, a tal punto que la expresa con una metáfora desgarradora: las ovejas son "tan feroces y tragonas que hasta engullen hombres, y después, destruyen y devoran campos, casas y ciudades" (Moro 2011 57).

Lo que está detrás de tales palabras no resulta exagerado si recordamos los profundos cambios que conllevaron el abandono de un modelo de acumulación centrado en la agricultura y el nacimiento de otro vinculado a la gran explotación textil que caracterizaría a los siglos venideros (Gerard y Sterling). Como es harto conocido, tal transformación habilitaría un nuevo modo de producción que terminaría aniquilando al feudalismo y conectando las distintas coordenadas del mundo como nunca antes en la historia. Moro es testigo y exponente de que ello trae aparejado una variación fundamental en los modos de concebir al espacio. No casualmente, numerosos comentaristas destacaron que la conquista de América resultó sumamente significativa para la elaboración de Utopía, a tal punto que el propio personaje de Rafael es un tripulante de las expediciones de Américo Vespucio ${ }^{4}$.

Pero lo que debemos retener de esta denuncia del autor británico sobre el proceso de privatización de las tierras son sus consecuencias, tales como las migraciones urbanas, las ocupaciones de bosques, los aprovechamientos comerciales de distinta índole - como la usura y la especulación-, el desempleo, el hambre y el pillaje. Moro no se ocupa de desglosar cada una de ellas, sino de remitirlas a una misma fuente de inequidad, a un único gran problema que les da vida. Así, su mirada se posa sobre el tratamiento gubernamental de las inequidades. Allí es donde se encuentra al verdadero responsable de habilitar y de enmascarar las injusticias (Moreau; Rossi).

El razonamiento ofrecido por Moro es el siguiente: si grandes masas poblacionales han sido desterradas, libradas a su suerte, ¿de qué

4 Sobre la influencia del explorador florentino existe una larga bibliografía: Carolina Martínez (2017), Lewis Mumford, Mauricio Onetto Pavez, María Cristina Ríos Espinosa, Jean Servier y Geraldo Witeze Junior. Cabe señalar que este aspecto le sirvió al ensayista argentino Ezequiel Martínez Estrada (1963) para afirmar, en claro tono apologético, que el proyecto de Utopía comenzaba a ser posible en Cuba a partir del triunfo castrista. El decir de Moro, sin embargo, ya había sido recuperado siglos atrás para pensar el nuevo continente, sobre todo a partir de Vasco de Quiroga (Idoya Zorroza; Sánchez Juárez 2017). 
modo podrán proveerse los medios de sustentación? ¿Cómo es posible que se intente solucionar tal coyuntura angustiante castigando a cualquier delito de la misma manera, es decir, con la pena de muerte? Para nuestro pensador, se trata de una medida "demasiado cruel" y demasiado insuficiente "para evitarlo", pues "el simple robo no es delito tan grande que deba ser castigado con la muerte, y ninguna pena será suficientemente dura para impedir que roben los que no tienen otro medio de no morirse de hambre" (Moro 2011 53).

En ese marco, Moro se ocupa de contrarrestar la consideración en boga sobre la delincuencia: los asaltantes - esos antiguos campesinos hoy hambrientos- son ociosos, personas que no quieren trabajar y por ello deciden apropiarse del trabajo de otros. Desde la óptica del autor, en cambio, ociosos son aquellos que, como dirá siglos después Emmanuel-Joseph Sieyès en ¿Qué es el Tercer Estado? [1789], viven del trabajo de los sectores laboriosos. En este sentido, la crítica más mordaz de la obra se lee precisamente en aquel pasaje donde Rafael relata lo acontecido en la casa de John Morton - protector del propio Moro en su juventud ${ }^{5}-$, más específicamente, cuando un bufón, en plena cena y amparándose en su oficio de hazmerreír, afirma que los frailes son los "mayores vagos del mundo" (Id. 70).

Ahora bien, si en la Inglaterra de principios del siglo XVI cualquier delito acarrea la muerte, todo aquel que se dirija a robar elegirá asesinar para no dejar testigo alguno que pueda incriminarlo:

Cuando el ladrón sabe que el riesgo que corre es el mismo si ha robado que si ha cometido un homicidio, se ve incitado a hacer desaparecer a aquel que, en otro caso, sería sólo despojado; ya que, si se le aprehenden, el peligro de ser ahorcado es el mismo, mientras que el asesinato ofrece mayor seguridad: puede hacer esperar que el crimen quedará oculto al suprimir al posible testigo (Id. 64).

Así, los crímenes y las ejecuciones se multiplicaban sin resolverse sus causas últimas. Esta incapacidad advertida desemboca directamente en la imputación de "mal gobierno" que Moro efectúa en su escrito, es decir, en la admisión del carácter injusto de la administración

5 Si bien abundan trabajos sobre aspectos biográficos del autor, se recomienda consultar los clásicos de Edward Surtz y Anthony Kenny, y aquellos más recientes de Hernán Corral Talciani (2010 20112016 2018). 
penal, en un juicio descarnado acerca de lo imprudente de mantener milicias regulares que buscan anexar nuevos territorios sin pretender lidiar correctamente con los que ya se poseen. En definitiva, con la aseveración de que en el mundo domina un paradigma rapaz y ruin, que concibe a la vida en común como una suerte de posesión sobre cosas y animales: "cuando uno sólo vive en el lujo y los placeres mientras a su alrededor todo son lamentos y gemidos, cuida de una cárcel y no de un reino" $(I d .81)^{6}$.

Y aquí se verifica un quiebre en el relato que propone el pensador británico; quiebre que se trata menos de una debilidad de su pluma que de una de las marcas características de la tradición que inaugura, a saber, la renuncia a mostrar cómo se debe articular una política destinada a eliminar tales flagelos. En otros términos, la ausencia de explicación sobre cómo hacer realidad eso que se desea, que se presenta como Eutopía, es decir, como "un buen lugar"7. Este rasgo, que posteriormente será tomado como agravio cuando se juzgue a proyectos políticos como utópicos, es el signo de que las utopías son políticas no por su apelación a la concreción, sino porque su admitida no-concreción devela una crítica a lo existente y, en el caso específico del texto de Moro, un modo sugerente de concebir lo político ${ }^{8}$.

Las utopías presentan una imagen deseable, pero estática de cómo el mundo debería ser, una verdadera Eudaimonía que se contrasta con el ideal de la eficacia que caracterizaría a la razón de Estado (Meinecke). No intentan, como sucede en República de Platón, efectuar solo

6 Esta cuestión, que obviamente acarrea a su contracara, es decir, al "buen gobierno", ha sido fundamental para pensar el ejercicio del poder desde la Antigüedad -recuérdese Aristóteles- hasta nuestros días (Abellán López), pasando también por el problema de la tiranía en el decir de Tomás de Aquino (2003) y las discusiones propias del republicanismo (Skinner). En lo que concierne a los siglos XV y XVI, apareció asociada al uso de la razón y al derecho natural, lo que terminaría siendo crucial para la discusión sobre el estatuto de los herejes y de los indios - en pensadores como Francisco de Vitoria y Bartolomé de las Casas-y para la posterior tradición contractualista.

7 Se ha destacado que, en inglés, "Utopía” y "Eutopía" dan lugar a una homofonía (Bidegain Ponte).

8 No en vano, al referirse al socialismo utópico, Karl Marx y Friedrich Engels pensaron en Proudhon, Babeuf, Owen, Fourier y Saint-Simon, y no en Moro, a quien no mencionan en su Manifiesto comunista [1848]. En este sentido, cabe mencionar que Ernst Bloch procuró recuperar el rol de la utopía en el marxismo, para lo cual distinguió aquellas utopías abstractas de aquellas con capacidad de transformación. Así, Moro apareció ante sus ojos como el creador del término, mas no como su verdadero desarrollador conceptual. 
una crítica que se ampara en un paradigma filosófico que pretende aplicar la verdad de la Idea en el mundo, algo que de igual modo está destinado a perecer. Utopía es una utopía porque su apuesta no reside solo en la dualidad geográfica ya advertida que posibilita la crítica, sino porque en esa dualidad, que hace suya, se verifica una relación particular con el tiempo; una relación que vuelve a la isla diagramada no solo en un no-lugar sino en un no-tiempo, debido a que ya no tiene sentido alguna la política.

Fredric Jameson ha destacado que la división topográfica a la que hacemos alusión distingue a las primeras utopías - como la de Moro, La ciudad del sol [1602] de Tommaso Campanella y La Nueva Atlántida [1627] de Francis Bacon- de las que se sucederían tiempo después, acaso más preocupadas por marcar un salto temporal en el relato poniendo el acento en el futuro 9 . Y en esto coincidirían escritos como el de Louis-Sébastien Mercier intitulado El año 2440 [1770], pero también aquellos distópicos tan célebres del siglo XX — como 1984 [1949] de George Orwell, por solo mencionar a uno-. Pero lo que Jameson no destaca con su aseveración es que lo temporal es crucial para comprender un texto como el que aquí nos ocupa, pues la organización social que se presenta en Utopía como justa es perfecta porque domina al tiempo, porque desactiva su componente disruptivo. Esto no significa que los utopianos vivan fuera de él, en una suerte de eternidad, sino que su impacto y sus efectos resultan irrelevantes para la vida social, ya que han llegado a una suerte de fin de la historia que niega toda novedad y todo cambio.

Veamos a continuación cómo ello se manifiesta en la particular forma de organización de los magistrados que asume la isla.

\section{Una forma impolítica}

Como bien indicó John Davis, a diferencia de otros modelos imaginarios - tales como "La tierra de Cucaña", en donde los apetitos se satisfacen por las bondades de la naturaleza, "Arcadia" en donde la armonía entre el hombre y su entorno es tal que la moderación marca el ritmo

9 Cabe señalar que esto ya había sido destacado por Karl Mannheim en 1929, más específicamente en un trabajo como Ideología y utopía: introducción a la sociología del conocimiento. 
de la vida, y la "República de la moral perfecta" o "el milenarismo", con su salvación colectiva por obra de una fuerza sobrehumana-, Utopía no versa sobre los hombres ni sobre el entorno de la naturaleza (Lizárraga), sino sobre la organización social. La diferencia que se plantea entonces, en este discurso de 1516, no radica en la posesión de dotes sobrenaturales o mágicos, sino en una mejor forma de vida que permite a sus habitantes desarrollarse "en medio de la mayor felicidad" (Moro 2011 91).

Tal como se describe en la segunda parte del escrito, la distribución de las horas entre las labores, el ocio y el descanso se encuentra zanjada y ajena a toda polémica. Los nativos "destinan seis horas al trabajo: tres por la mañana, después de las cuales van a comer; acabada la comida reposan dos horas, y luego trabajan otras tres horas, hasta el momento de la cena", y se van a "dormir a las ocho y duermen ocho horas" (Id. 109). Este tipo de reglamentaciones abundan en la descripción que Rafael ofrece en sus parlamentos. De hecho, hacen pensar que, a la luz de semejante organización, crónos se impone a kairós. Y con ello queremos decir que lo excepcional de la realidad aparece subsumido en el discurrir de un tiempo que nada dice más que la cumplimentación de los ciclos de nacimientos y decesos, sin que por otro lado estas variaciones impliquen tribulación alguna.

Sin embargo, Utopía enarbola una suerte de convicción: el mundo podría ser de otra manera siempre y cuando se lo organizase correctamente. En esta línea, el obstáculo que Moro avizora remite a que las distintas comunidades existentes se desangran en situaciones que no pretenden corregir. Pero, a diferencia de lo que se podría considerar desde perspectivas políticas realistas - que se arrogan la capacidad de entender cómo son realmente los hombres y no como deberían ser-, Moro ofrece una visión que no apela a una suerte de idealización del mundo, precisamente porque tampoco le brinda culto alguno a las virtudes humanas. Es evidente que, a pesar de ello, se distancia del realismo en tanto su utopía - como toda utopía- erradica el conflicto de la vida social, muestra una imagen estática de cómo las cosas deberían ser, sin decir nada sobre el pasaje a ese escenario delineado. He aquí un aspecto impolítico de este tipo de discursos.

De hecho, una vez señalada la causa fundamental de los problemas sociales - las inequidades económicas ya comentadas-, su remoción 
se da por sentada al narrarse ese espacio imaginario. Esto nos lleva entonces a plantear un interrogante capital para nuestro interés sobre el rol de la política en la trama de la obra, a saber: ¿qué sentido tiene el gobierno allí donde no hay disputas ni inconvenientes que resolver? ¿Qué hacen los magistrados en una comarca en la que existe una solución para cualquier problema que pueda surgir?

Recordemos: anulada la propiedad privada, distinguida como el error fundamental que lleva a una división social injusta, en tanto convierte a algunos en ociosos voluntarios y a otros en desposeídos y míseros, la isla de Utopía muestra una solución para cada inconveniente. A diferencia de lo que sucede en la Inglaterra del siglo XVI, en el país inexistente visitado por Rafael sus actividades económicas tienen como principal motor a la agricultura, que se ejerce de forma comunitaria a partir de una jornada laboral de seis horas. Esto, según el personaje portugués, no implica una baja de la productividad en tanto todos - absolutamente todos - trabajan. Es decir, el crecimiento cuantitativo de la mano de obra permite la reducción de la jornada laboral, lo que redunda en la posibilidad de dedicarse a otros menesteres ligados, por ejemplo, al mundo del espíritu ${ }^{10}$.

En este sentido, en Utopía no reina la añoranza de un pasado perdido o la nostalgia de una época finalizada. La imputación de su autor a la destrucción de la agricultura y su defensa en el desarrollo de su ficción no bastan para sostener algo semejante. Su escrito parece, en verdad, no estar movido por el intento de volver la historia hacia atrás, puesto que muchos de los aspectos criticados en el libro primero forman parte de la raíz misma del orden feudal, como es el caso de la ociosidad y el aislamiento principesco.

Tal como su admirado Platón, Moro señala a la propiedad privada como el origen del conflicto, pero, a diferencia de lo consignado en República, toda tribulación desaparece para no volver, para obturar

10 "Quizás pensaréis que una jornada de seis horas producirá necesariamente escasez. Más no es así. Tal jornada, no sólo basta para procurar lo necesario a las necesidades y comodidades de la existencia, sino que las excede. Y lo comprenderéis si consideráis cuán grande es, en los restantes países, la parte de la población que pasa el tiempo en la holganza" (Moro 2011 110). Moro parece replicar aquí no solo la comunidad de guardianes de República de Platón, sino también cierto ideal monástico que tanta influencia tuvo en su propia vida, al valerse él mismo de la disciplina propia de los monjes cartujos (Davis). 
toda posibilidad de fracaso. Así, no existe un axioma que marque la imperiosa corrupción de la materia y la degeneración de la nueva polis, como en el decir del filósofo ateniense. En Platón, el gobierno de los sabios resulta la traducción más perfecta del buen régimen, pero una traducción al fin, es decir, siempre falible, en tanto el mundo mismo en el que se despliega está sujeto a la corrupción. En cambio en Moro la organización vence al tiempo, porque el tiempo no tiene por qué vencer una vida que ha logrado acabar con los asuntos que desangran a las naciones realmente existentes.

Estos elementos son los que diferencian un proyecto político de raigambre filosófica, como el platónico, de una reflexión política utópica, como la moreana ${ }^{11}$.

$\mathrm{Al}$ recorrer lo indicado en el escrito de 1516 se tiene la sensación de que nada queda librado al azar, porque ya no hay abertura en el tiempo que habilite a lo incontrolable, porque, en otras palabras, ya no hay azar. Aun cuando los utopianos no sepan cómo será el futuro, cualquier cosa que este les depare recibirá una respuesta adecuada; una que ya ha sido contemplada por su forma de vida. La isla imaginada, por ende, se agota en la rutina, en la seguridad y la eficacia de un modo de ser ya probado. De hecho, solo se generan variaciones mínimas - como el recibimiento de viajeros- que no alteran en nada su organización. Se trata, en suma, de una verdadera negación a todo cambio; negación que estriba en un tipo particular de relación con el tiempo, caracterizada por su dominio. Esto es lo que lleva a interrogar las características e implicancias de su régimen de magistrados.

En el poco extenso tercer capítulo de la segunda parte del libro, Moro indica que las familias eligen a un sifogrante, que un conjunto de sifograntes tiene como representante a un traniboro, pero que son aquellos quienes eligen al príncipe - cargo vitalicio- entre cuatro candidatos propuestos por el pueblo, y que los cargos se renuevan tras un cierto periodo de tiempo. Las elecciones parecen establecerse a partir de un mecanismo que va de "abajo hacia arriba", pero su celebración no provee a los lectores de la obra de coordenadas muy precisas

11 Como se comprueba en distintos pasajes de Utopia, es notoria la influencia de Platón. Ya Leo Strauss (2006) supo marcar esta línea de continuidad, aun sin tratar en detalle de la obra de Moro. Al respecto, ver: José Luis Galimidi y Oscar Donato. 
sobre su real incidencia en la política. De hecho, toda esta descripción vuelve aún más imperiosa la pregunta sobre el tipo de régimen que en verdad existe en Utopía. ¿Acaso se trata de una democracia debido al papel del pueblo? ¿De una monarquía por la presencia de un príncipe? El punto es que esta heterogeneidad de rasgos indica menos un régimen de nuevo tipo que la necesidad de pensar la verdadera naturaleza que Moro le asigna a lo político.

Es que al apelar a tipologías clásicas para describir este sistema de magistrados - como las de Platón, Aristóteles, Polibio o cualquier otro filósofo de la Antigüedad, que de seguro Moro conocía muy bien- se llega a una irresolución. O, peor aún, a un límite que no permite observar la radicalidad del gesto teórico propuesto por el autor. Pues su decir conduce a la presunción de que no hay categoría alguna de la filosofía que pueda asemejarse al modo de organización de la isla. Es, si se quiere, un sistema de lo indecible. Esto se expresa de forma clara allí cuando se deja de concebir a los sifograntes, traniboros y hasta el mismísimo príncipe como figuras estrictamente políticas.

Para ser más claros, Moro parece construir un sistema de gobierno, pero en verdad no es tal. Es una suerte de artificio que permite posar la mirada hacia la forma de vida de la isla y no hacia mecanismos institucionales que no existían en la realidad, y que, por tanto, no podían ser designados con otro nombre más que con aquél con el que bautizó a su propia obra ${ }^{12}$.

Anulado el conflicto, sentadas las bases de una organización social justa, en la isla de Utopía no hay estructura decisoria alguna, no hay política -0 , al menos, no en el sentido que estamos acostumbrados a verla-. Lo que queremos remarcar con esto es que es en la vida social de Utopía, y no en el sistema de los magistrados, donde descansa la política que anula al tiempo.

Visto de este modo, los funcionarios no son más que un apéndice de la verdadera institución fundamental: la familia, es decir, la entidad donde se gestan y se celebran las uniones matrimoniales, se edu-

12 Recordemos que la nominación del régimen no es un problema de terminología, pues en la obra abundan creaciones de este tipo, no solo desde su título, sino en sus páginas, tales como Anidro - que significa "río sin agua" - , la capital de los utopianos Amaurota - "ciudad que no se ve"-, Acortia - "el país sin territorio"-, etc. 
ca a los niños, se controlan los cultivos y alimentos, y se comprueban las conductas de los hombres y las mujeres que habitan en las casas numerosas de las distintas ciudades. Los magistrados solo extienden permisos, firmas, formalidades que permiten traslados o recibir a embajadores de otras naciones; solo son quienes ponen en marcha los contactos con mercenarios cuando la posibilidad de guerra se aproxima, y quienes emprenden actividades ya protocolizadas, ya definitivas, lo que significa que lejos están de ser una elite de gobierno. En este sentido, no hay dominación alguna que sostener, ya que la dominación se ha hecho carne en todos y en cada uno de los habitantes. El príncipe, por caso, es solo una figura decorativa, que lleva en sus manos - como lo indica el propio Rafael— un ramo de flores para que se sepa quién ocupa el cargo ${ }^{13}$.

Entonces, ¿cuál es el área de competencia de los magistrados allí donde no hay nada sobre lo que decidir? Simplemente aplicar instancias definitivas, ya insertas en la tradición de una organización social efectiva, perfecta, tejida desde el propio seno familiar. No por nada, frente al peligro existencial de la guerra, Moro indica que los utopianos tienen en claro cuándo y cómo ponerse frente a los ejércitos, cuándo y cómo causar intrigas en el enemigo para debilitarlo, corromperlo o vencerlo a través de mercenarios, y cuándo y cómo colonizar nuevos territorios si así lo necesitasen ${ }^{14}$.

En suma, ni en el momento dramático y angustiante bélico hay, en la isla, un espacio abierto de decisión política. Así, lo imaginable condensa a lo imposible ${ }^{15}$.

Estamos en presencia de una forma impolítica de régimen, que tiene como contracara una introyección política de las normas de vida que cuestiona la idea de individuo y de singularidad, es decir, la agencia misma de los sujetos. Esto, que trataremos en el siguiente apartado,

13 De allí que también haya sido leída como un verdadero modelo de sociedad disciplinaria foucaultiana (Bidegain Ponte).

14 Siguiendo a Hannah Arendt, Ursula Niklas encuentra en Moro una negación de la política vía una economización de la vida a partir de la importancia de la labor.

15 Sobre el tópico bélico, Moro mostró dos caras: en el libro primero lo condena, mientras que en el segundo lo justifica si las necesidades así lo requieren, por más que los utopianos consideren a la guerra como una "cosa bestial" y "abominen de ella", y estimen, "al revés de la mayoría de los demás pueblos", "que no hay cosa más despreciable que la gloria guerrera" (Moro 2011 165). 
comienza a ser evidente cuando se entiende por qué en la isla existe la pena de muerte para muy pocos casos; pena que es condenada por el autor a lo largo del libro primero. La explicación de ello reside en que ciertos delitos dañan al tejido comunitario. De hecho, en la isla de los utopianos solo se aplica para la reincidencia en el adulterio y la discusión de asuntos públicos en ámbitos privados.

En relación al adulterio, Moro remarca que afecta directamente a la familia. Recuérdese que, al momento de elegir cónyuge, los utopianos gestan todo un ritual que hace que el hombre y la mujer se presenten en una habitación desnudos, bajo supervisión de dos adultos que evitan el acceso carnal, para que cada uno examine en detalle a su pretendiente. Esto, que parece un tanto ridículo, muestra, en verdad, la importancia de este tipo de lazo, pues es fundante de la sociedad. Se trata de una suerte de inspección física a la que los pretendientes se someten para reducir inconvenientes futuros, una vez ya consagrada la unión. Por ello también es que está contemplada la posibilidad de divorcio, tanto en el caso de que los caracteres sean incompatibles como ante un hecho de adulterio. Existe, empero, la posibilidad de perdonar la falta del amante, pero no cuando se repite, pues debilita la integridad social que se cifra en la familia. De manera que, ante la reiteración, el infractor debe pagar su aventura con su vida.

El segundo caso en el que se aplica la pena de muerte no es menos revelador que éste; de hecho, ejemplifica muy bien lo que hemos dicho sobre el carácter no político de los magistrados: éstos, bajo ningún punto de vista, pueden deliberar "sobre los negocios públicos fuera del Senado o de los comicios públicos", ya que se trata de evitar que "el Príncipe pudiera fácilmente oprimir al pueblo y modificar el régimen, de acuerdo con los traniboros" (Moro 2011 106), es decir, producir algún tipo de variación que introduzca un verdadero régimen político, uno que domine a otros.

Esta forma de administración revela que nada novedoso puede darse en la nación ideada por Moro. Acaso por ello debemos recordar que solo un único hombre se registra en la memoria isleña: su fundador, Utopo, quien conquistó el territorio y lo separó del continente. Esta carencia de novedad y de relevancia aparece ya condensada en pasajes en los cuales el propio Moro expresa que la disputa entre particulares es "cosa rara" (Id. 105) en la isla, tanto como que las monedas 
acopiadas sirvan en algún momento para prevenir "acontecimientos" que, "acaso, nunca se realizarán" (Id. 126). De allí que hayamos dicho que en Utopía nada se altera, nada tampoco se destaca; cuestión que nos conduce a interrogar, precisamente, el tipo de vínculo que se teje entre la comunidad y sus integrantes.

\section{El lugar del individuo}

Si una utopía como la de Moro hace hincapié en la organización, y si esa organización no estriba en un régimen político sino en la comunidad toda como forma de vida, se vuelve menester indagar en su funcionamiento. El subtítulo de la obra resulta fundamental para comenzar a hacerlo, pues entrega ciertas pistas que refuerzan lo ya dicho, al mismo tiempo que abre interesantes puertas sobre algunos de estos aspectos complementarios de los que, precisamente, nos ocuparemos ahora.

Como se sabe, en su primera edición —en idioma latín- el escrito de Moro contó con la siguiente titulación: De optimo reipublicae statu deque nova insula Utopia. Tras unos años, finalmente apareció en lengua inglesa, apelando a la noción de Commonwealth por la de respubli$c a$. Luego pasó a desconocerse casi por entero todo este largo nombre, destacándose simplemente un término, aquél por el cual sería recordada: Utopía ${ }^{16}$.

Las nociones de respublica y Commonwealth destacan que su autor parecía estar pensando más en la organización misma de lo social, en su forma entera, que en un sistema político en particular $^{17}$, ya que toda la comunidad de Utopía es lo relevante y no un grupo de magistrados que, en verdad, no deciden sobre nada.

De hecho no deciden, puesto que los mecanismos de control se encuentran tan sólidamente diseñados que no solo sustraen la posibilidad de la política vía la negación del conflicto, sino que además la vida es tan rutinaria que no hay historia alguna que contar. Aunque el propio Moro exprese que los utopianos poseen ciertos anales que registran sus hechos memorables, los mismos versan únicamente sobre el

16 Para más información sobre las distintas ediciones, ver: Peter R. Allen.

17 A diferencia de la utopía de James Harrington -The Commonwealth of Oceana [1656]- que sí hace hincapié en el modelo republicano de organización. Sobre el particular: Lucas Misseri (2011). 
momento de desarrollo de la isla, cuando - si se nos permite el juego de palabras- Utopía aún no es una utopía. Por este motivo describe, de forma bien sucinta, el momento fundacional del país y los rasgos generales de su evolución urbana que le permitan llegar al punto neurálgico de su relato, a saber, la descripción de una imagen acabada de un espacio inexistente.

En consecuencia, una vez asentada la organización utopiana, todo es tan rutinario, tan igual día tras día, que el conocimiento del griego, la producción en serie de libros y la lectura de los pensadores más importantes de la tradición occidental no cambian en nada su forma de existir. Nada magnífico o extraordinario sucede en Utopía ${ }^{18}$.

En este sentido, bien vale recordar lo que Roberto Esposito describe en su libro Communitas, en especial aquellas páginas que indican que los miembros de la comunidad tienen una relación de obligación y de deuda para con ella, por lo que no pueden pensarse por fuera de su estructura. Esto que Esposito retrotrae al mundo romano y conduce hasta el nazismo, nos sirve aquí para ver una inconfundible marca temporal que cifra la innovación de Moro en un tiempo en el que se pondrá en juego, precisamente, la verdad de la subjetividad como principio universal, aquello que Hegel ubicará en Filosofía del Derecho [1821] a partir del avance del cristianismo, de la Reforma protestante y, más aún, de la Revolución francesa, es decir: el valor del individuo y la tensión que conlleva su emergencia entre la esfera pública y la privada. Esta cuestión nos sirve para alumbrar una arista que excede el sentido atribuido por Esposito, en tanto si algo parece mostrarse en el texto de 1516 de Moro es una homogeneidad que tiñe de gris a esa sociedad ideal, que hace que todos los individuos sean iguales, que no existan en su singularidad, que no haya deuda que aplicar porque no hay nada que pagar ni reparar.

La organización de la isla hace, entonces, que no haya virtudes que destacar, ningún gesto extra-ordinario que ponderar. A excepción del soberano de antaño, ningún otro nombre propio es relevante, ni pa-

18 En esto, por tanto, nos apartamos de Miguel Abensour (2003), quien destacó que la utopía es historia no realizada. Claro que hay que recordar que sus palabras remiten a una resignificación del concepto en pleno siglo $\mathrm{XX}$, a partir de una deriva autonomista de la política. 
rece que podrá serlo jamás, puesto que el tiempo carece de impacto. Los utopianos se visten, piensan y actúan todos igual, o de una forma muy similar, tanto que los matices que los pueden hacer diferentes no conllevan que verdaderas individualidades emerjan o sobresalgan. No en vano Utopía ha sido leída como una profunda crítica a la moral republicana del humanismo italiano, tan preocupada por destacar la labor de los grandes hombres (Nelson 2001 2006), por remarcar la importancia de la agencia.

En este sentido podríamos aseverar que la contracara necesaria de una organización semejante - que nada decide - es esta opacidad del individuo ya indicada. Es como si Moro, en los albores de la Modernidad, apelara a una suerte de eticidad griega antigua, que le permitiera inscribir el accionar de los sujetos en la comunidad para, al mismo tiempo, reafirmar que ese ideal es imposible si cada individuo no introyecta el orden, si no desaparece en él, tal como se podría rastrear en ciertos ideales cristianos. Siguiendo esta línea de indagación, el fuero interno aparece no como imposibilidad última de la soberanía absoluta -como verá Carl Schmitt en su célebre texto sobre el pensamiento de Thomas Hobbes, es decir, como origen del liberalismo y de la defensa de la persona-, sino como garantía de una forma de vida que no puede ser alterada.

Si bien se puede argumentar que Moro da cuenta de la tolerancia religiosa (Hermida del Llano; Huerta Rodríguez; Svensson), se trata de algo que es bien acotado, pues todos los utopianos creen en la inmortalidad del alma y en la existencia de un único Creador (Kessler). Por lo tanto, más que habilitar una suerte de relativismo cultural, se trata de una homogenización que permite que vayan "abandonando poco a poco esta diversidad de creencias, para comulgar en una sola religión que aparece a la razón como superior a las demás" (Moro 2011 179) ${ }^{19}$.

De hecho, este proceso, en apariencia plural, está regulado por otros mecanismos, inclusive de raíz pagana, que indican la presencia de importantes instancias de control. Así, las almas de los muertos pueden "vagar por donde quisieren" controlando los momentos de

19 También se podría encontrar aquí una recuperación de la ley natural, en la que se establece la posibilidad de encontrar a Dios mediante la razón y de expresarlo, en términos positivos, bajo distintas maneras (Bloch). 
soledad de los vivos y regulando que éstos no den rienda libre a sus deseos más pecaminosos o a sus acciones más perniciosas cuando están en soledad (Saralegui). Por ello - comenta el propio Rafael一, los utopianos creen que "los muertos mézclense con los vivos y son espectadores de sus hechos y dichos"; por lo que no hay "ocasión de corruptelas, ni escondrijos, ni reuniones ocultas, ya que, estando todos bajo la mirada de los demás, vence obligados a dedicarse al trabajo habitual o a un honesto holgar" (Moro 2011 124). En suma, "la creencia en la presencia de sus mayores les impide realizar en secreto malas acciones" (Id. 184).

El último elemento que quisiéramos marcar en este sentido remite, precisamente, a la única posibilidad de agencia que se verifica en Utopía; posibilidad, sin embargo, que por sus propias características, está destinada a agotarse.

Como se sabe, Moro condenó fuertemente al suicidio, quizás debido al peso de la tradición cristiana en sus consideraciones (Gueguen) - pues "Dios nos prohíbe no sólo quitar la vida a nuestros semejantes, sino quitárnosla nosotros mismos" (Moro 2011 196)-, aunque su filiación religiosa parece ser un recurso explicativo que debe ser matizado, ya que el propio autor no tuvo reparos en admitir, por ejemplo, la eutanasia (Misseri 2012). De hecho, recuérdese cómo al paciente que representa ya una molestia para la comunidad, "los sacerdotes y magistrados" lo "exhortan" diciéndole que, "puesto que ya no puede realizar ninguna cosa de provecho en la vida y es una molestia para los otros y un tormento para sí mismo" no debe "dudar en morir", lleno de "esperanza de librarse de una vida acerba cual una cárcel y de un suplicio, o en permitir que otros le libren de ella". Así, "los que son persuadidos se dejan morir voluntariamente de inanición o se les libra de la vida durante el sueño sin que se den cuenta de ello", aunque este fin no se le "impone a nadie" (Moro 2011 153).

Sin embargo, nada se puede hacer contra el suicidio. Quienes lo efectúan quedan lejos del dominio de sus compañeros de isla; lejos de los mecanismos que establece la familia; lejos de las acciones administrativas de los magistrados. Por ello es importante pensar que esa reacción extrema es una afrenta hacia la comunidad, hacia el valor mismo de una utopía que se precia de su perfección, de su dimensión deseable. Ante el suicidio, todo lo diagramado se vuelve impotente, 
se cuestiona, tanto como se reafirma. De alguna manera, por ridícula que ésta sea, Moro encuentra una forma de positivizarlo en términos sociales, de valerse de él para efectuar un impacto que controle a los vivos: "si alguien se diera la muerte sin causa reputada válida por los sacerdotes y el Senado, no es considerado digno de la tierra ni del fuego. Su cuerpo, privado ignominiosamente de sepultura, es arrojado a los pantanos" (Ibíd.).

Así, la politicidad de este hecho se verifica de una manera doble: primero, en el acto de negación y de descontento ante la comunidad que lleva a cabo el suicida; segundo, en la transformación de ese descontento por la comunidad, ya que el cadáver sirve para producir un efecto de horror o de impresión sobre los vivos, espantando así el efecto contagio. De modo que la política vuelve a ser negada en tanto el gesto suicida no genera un cambio o un lazo que posibilite rebelión o disenso alguno; se trata solo de una dimensión partisana, de un descontento solitario, que nada puede producir en términos sociales.

De todos modos, cabe plantearse, efectivamente, ¿quién podría decidir quitarse la vida en un país sin conflictos, desigualdades o injusticias? ¿Quién optaría por un camino semejante allí donde la organización social es perfecta, todopoderosa? Reaparece entonces una de las aristas características del género utópico: la obturación del conflicto y su movimiento. Es decir, la presentación de una imagen sobre cómo la vida debería ser; presentación que es inmune a toda variación o disrupción en tanto se trata de una empresa acabada.

\section{Consideraciones finales}

El trabajo que aquí concluye tuvo como principal objetivo pensar la política en Utopía, asociándola a las características de un discurso que plantea una relación específica entre espacialidad y temporalidad. En este sentido, propusimos leer la reflexión de Moro como una empresa que termina derivando la política hacia una forma de vida comunitaria sin conflictos y sin variaciones. De manera que Utopía presenta un paisaje logrado sobre una forma de vida feliz en la que impera una organización social perfecta, que prescinde de un gobierno en sentido estricto, puesto que no hay espacio alguno para la variabilidad o la contingencia que toda decisión sobre los asuntos públicos conlleva. 
En ese marco, nos interrogamos precisamente sobre la agencia del individuo, puesto que, en el relato, se destaca un modelo familiar que parece obturar la singularidad del sujeto. En este punto, sin embargo, cabe indicar un aspecto subsidiario a lo ya analizado, que repara en la particularidad del género que inaugura Moro y su inscripción fundamental en el terreno de la crítica. Quisiéramos, entonces, proponer ahora una última y breve reflexión.

Para ello vale la pena recordar un pasaje del escrito en el que el personaje de Moro le reclama a Rafael por qué no se convirtió aún en consejero de reyes y gobernantes, ya que su sapiencia lo amerita. Éste se niega rotundamente a ello, aduciendo la terquedad y el carácter ruin que asumen los asuntos palaciegos. Tras ello, Moro se adjudica las siguientes palabras: "ya sabéis cuál es la opinión de vuestro amado Platón: solamente serán felices los pueblos del futuro cuando los filósofos se conviertan en reyes y los reyes en filósofos. ¡Cuán lejana está aún semejante felicidad, si los filósofos no se dignan asistir a los reyes con sus consejos!" (Id.73); palabras que, como contrapartida, reciben, algunas páginas más adelante, una respuesta taxativa de parte del navegante: "no hay lugar para los filósofos en la Corte" (Id. 83).

Este gesto sutil del escrito termina siendo sumamente develador pues, en definitiva, el de Rafael no es un saber ligado al conocimiento filosófico o científico, es un saber de la experiencia, pero un saber que no se esgrime en las plazas públicas como lo hacía tiempo atrás Sócrates, sino en la intimidad de una conversación entre hombres cultos, entre dos figuras humanistas, entre dos letrados, como Pedro Egidio y el propio Moro. Este gesto de privacidad que dio vida al diálogo resulta sumamente sintomático del modo de reflexionar de los exponentes del género utópico, ya que nada queda más sujeto a la unilateralidad de la individualidad que la explicitación de un deseo, por más igualitarista o inspirador que este sea. En definitiva, "la utopía" no es más que "una obra muy personal e idiosincrática", no es más que "la creación distintiva de un autor" (Ricoeur 57).

\section{Bibliografía}

Abellán López, María Ángeles. “Del cielo normativo a la tosca materia. La transformación discursiva del buen gobierno en gober- 
nanza", Foro Interno: Anuario de Teoría Política, 17 (2017): 55-72.

Abensour, Miguel. “Utopía y democracia”, Polis, 6 (2003): 1-10.

Allen, Peter R. "Utopia and European Humanism: The Function of the Prefatory Letters and Verses", Studies in the Renaissance, 10 (1963): 91-107.

Aristóteles. Política. Madrid: Gredos, 1988.

Beuchot, Mauricio. "El porvenir político-cultural y escatológico del hombre según Paul Ricoeur: utopía y ontología", ISEGORÍA, 5 (1992): 134-142.

Bevington, David. “The Dialogue in 'Utopia': Two Sides to the Question", Studies in Philology, 58/3 (1961): 496-509.

Bidegain Ponte, Germán. "La Utopía de Tomás Moro: Una sociedad disciplinaria", Revista Pléyade, III/6 (2010): 2-26.

Bloch, Ernst. El principio esperanza. Vol. I, II y III. Madrid: Aguilar, 1980.

Bouyer, Louis. Tomás Moro. Humanista y mártir. Madrid: Encuentro, 1986.

Comparatto, Vittor. Utopía: léxico de política. Buenos Aires: Nueva visión, 2006.

Corral Talciani, Hernán. "Contribución a la historia de la libertad de expresión parlamentaria: el discurso de Tomás Moro como Speaker del Parlamento inglés de 1523", Estudios Constitucionales, 9/2 (2010): 429-452.

Corral Talciani, Hernán. “Qui tacet consentire videtur. La importancia de una antigua regla canónica en el juicio contra Tomás Moro", IUS CANONICUM, 51 (2011): 137-160.

Corral Talciani, Hernán. "Tiranía y derecho en la declamación de Tomás Moro en respuesta al tiranicida de Luciano", Verbo, 541-542 (2016): 63-99.

Corral Talciani, Hernán. “Tomás Moro: entre la ley y la conciencia”, Revista Jurídica Digital UANDES, 2/1 (2018): 105-112.

Cuesta, Micaela. “Utopía, la cité. Una lectura sociológico pragmatista de Tomás Moro", Utopía: 500 años. Pablo Guerra (Ed.). Bogotá: Ediciones Universidad Cooperativa de Colombia, 2016. 3-25.

Davis, John. Utopía y la sociedad ideal. Estudio de la literatura utópica inglesa. 1516-1700. México: Fondo de Cultura Económica, 1985. 
De Aquino, Tomás. Del reino. Buenos Aires: Losada, 2003.

Donato, Óscar. Platón desplatonizado. Una interpretación de la lectura straussiana de la filosofía política de Platón. Buenos Aires, Prometeo, 2018.

Engeman, Thomas. “Hythloday's Utopia and More's England: an Interpretation of Thomas More's Utopia", The Journal of Politics, 44/1 (1982): 131-149.

Esposito, Roberto. Communitas. Origen y destino de la comunidad. Buenos Aires: Amorrortu, 2005.

Fueyo, Jesús. "Tomás Moro y el utopismo político", Revista de estudios políticos, 86-87 (1956): 61-108.

Galimidi, José Luis. "Ensayo de un acercamiento straussiano a la Utopía de Tomás Moro", Revista SAAP, 8/2, (2014): 585-608.

Gerard, W. B. y Sterling, Eric. "Sir Thomas More's Utopia and the transformation of England from absolute monarchy to egalitarian society", Contemporary Justice Review, 8/1 (2005): 75-89.

Gueguen, John. "Reading More's 'Utopia' as a Criticism of Plato", $A$ Quarterly Journal Concerned with British Studies, 10 (1978): 43-54.

Heiserman, A. R. "Satire in the Utopia", PMLA, 78/3 (1963): 163-174.

Hermida del Llano, Cristina. "Exigencias de la justicia natural en Tomás Moro", Persona y Derecho, 75 (2017): 257-284 .

Huerta Rodríguez, Jesús Caos. "El trasfondo cristiano en la Utopía de Tomás Moro", EPOS, XXXIII (2017): 245-261.

Idoya Zorroza, María. "La utopía renacentista y el modelo de Vasco de Quiroga", Tomás Moro y Vasco de Quiroga. Utopías en América. Virginia Aspe Armella (ed.). Pamplona: Eunsa, 2017. 97-114.

Jameson, Fredric. "La política de la utopía", AdVersuS: Revista de Semiótica, 6-7 (2006): 37-54.

Kenny. Anthony. Tomás Moro. México: Fondo de Cultura Económica, 2014.

Kessler, Sanford. "Religious Freedom in Thomas More's 'Utopia”, The Review of Politics, 64/2 (2002): 207-229.

Le Guin, Úrsula. “Pensar la Utopía”, Utopía, Tomás Moro, Barcelona: Ariel, 2016. 235-300.

Lizárraga, Fernando. "Política, justicia y comunidad en Utopía", Anacronismo e Irrupción, 8/15 (2018): 121-146. 
Martínez Estrada, Ezequiel. "El nuevo mundo, la Isla de Utopía y la Isla de Cuba", Cuadernos Americanos, 127/2 (marzo-abril 1963): 89-122.

Martínez, Carolina. "El impacto del Nuevo Mundo en la invención de Utopía de Tomás Moro", NÓMADAS, 47 (2017): 137-151.

Meinecke, Friedrich. La idea de la razón de Estado en la Edad Moderna. Madrid: Centro de Estudios Constitucionales, 2014.

Misseri, Lucas. "Morir en Utopía: Tomás Moro y la eutanasia", Bios y Sociedad I: Actas de la I Jornadas Interdisciplinarias de Ética y Biopolítica. Eduardo Assalone y Paula Bedin (comps.), Mar del Plata: Universidad Nacional de Mar del Plata, 2012. 419-425.

Misseri, Lucas. "Harrington y Hume: utopía, república y propiedad privada". Discusiones en torno a la Naturaleza Humana. Homenaje a David Hume. R. Pulley y N. Charri (comps.), Mar del Plata: Universidad Nacional de Mar del Plata, 2011. 702710 .

More, Thomas. Utopia. New York: Norton Critical Edition, 1992.

Moreau, Pierre. La Utopía. Derecho natural y novela del Estado. Buenos Aires: Hachette, 1986.

Moro, Tomás. Utopía. Traducción de Emilio García Estebanez. Madrid: Técnos, 2017.

Moro, Tomás. Utopía. Traducción de Joaquim Mallafrè Gavaldà y Vicente Campos. Barcelona: Ariel, 2016.

Moro, Tomás. Utopía. Traducción de Ramón Esquerra. Madrid: Círculo de Bellas Artes, 2011.

Mumford, Lewis. Historia de las utopías. México: Fondo de Cultura Económica, 2013.

Nelson, Eric. “Greek Nonsense in More's 'Utopia”, The Historical Journal, 44/4 (2001): 889-917.

Nelson, Eric. "Utopia through Italian Eyes: Thomas More and the Critics of Civic Humanism", Renaissance Quarterly, 59 (2006): 1029-1057.

Niklas, Ursula. "Utopia and Modern Times: Thomas More, Hannah Arendt, and Suppression of the Political", History of Philosophy Quarterly, 18/2 (2001): 207-226.

Onetto Pavez, Mauricio. "La utopía de Moro y la Isla Grande de Tierra del Fuego. "Una equivalencia posible", MAGALLANIA, 43/1 (2015): 37-51. 
Platón. República. Buenos Aires: Eudeba, 2004.

Prévost, André. Tomás Moro y la crisis del pensamiento europeo. Madrid: Ediciones Palabra, 1972.

Ricoeur, Paul. Ideología y utopía. Barcelona: Gedisa, 1989.

Ríos Espinosa, María Cristina. "La influencia americana: Utopías Europa y América", Estudios de Filosofía Práctica e Historia de las Ideas, 19 (2017): 1-14.

Rossi, Miguel. "La Utopía de Tomás Moro y el nacimiento del sujeto moderno", (En)clave Comahue, 22 (2017): 291-302.

Sánchez, Juan Antonio. “Utopía e ironía en el contexto de Tomás Moro”, Revista de Filosofía, 36/1 (2011): 29-51.

Sánchez Juárez, Cecilia. "El programa humanista en la utopía práctica de Vasco de Quiroga", Tomás Moro y Vasco de Quiroga. Utopías en América. Virginia Aspe Armella (ed.). Pamplona: Eunsa, 2017. 115-136.

Saralegui, Miguel. "La inmortalidad del alma: historia de un argumento político", Ideas y valores, LXIII/155 (2014): 85-106.

Schmitt, Carl. El Leviatán en la doctrina del Estado de Thomas Hobbes. Sentido y fracaso de un símbolo político. México: Universidad Autónoma Metropolitana, 1997.

Servier, Jean. La utopía. México: Fondo de Cultura Económica, 1995.

Skinner, Quentin. El artista y la filosofía política. El buen gobierno de Ambrogio Lorenzetti. Madrid: Trotta, 2009.

Strauss, Leo. La ciudad y el hombre. Buenos Aires: Katz, 2006.

Strauss, Leo. La persecución y el arte de escribir. Buenos Aires: Amorrortu, 2009.

Surtz, Edward. "St. Thomas More and His Utopian Embassy of 1515", The Catholic Historical Review, 39/3 (1953): 272-297.

Svensson, Manfred. “Tomás Moro, Utopía y la tolerancia en la tradición humanista", La Utopía de Tomás Moro: estudios jurídicos, filosóficos y literarios a 500 años de su publicación. Hernán Corral Talciani (de.). Chile: Universidad de los Andes, 2017. 99-106.

White, Thomas. "Festivitas, Utilitas, et Opes: The Concluding Irony and Philosophical Purpose of Thomas More's 'Utopia”, Albion: A Quarterly Journal Concerned with British Studies, 10 (1978): 135-150. 
Witeze Junior, Geraldo. "Como inspirado del espíritu santo: Vasco de Quiroga, primeiro intérprete americano da Utopia", Estudos Históricos Rio de Janeiro, 30/62 (2017): 535-554.

Wooden, Warren. "Anti-Scholastic Satire in Sir Thomas More's Utopia", The Sixteenth Century Journal, 8/2 (1977): 29-45. 